\title{
High static stability in the mixing layer above the extratropical tropopause
}

\author{
A. Kunz, ${ }^{1,2}$ P. Konopka, ${ }^{1}$ R. Müller, ${ }^{1}$ L. L. Pan, ${ }^{3}$ C. Schiller, ${ }^{1}$ and F. Rohrer ${ }^{2}$ \\ Received 2 February 2009; revised 29 May 2009; accepted 5 June 2009; published 27 August 2009.
}

[1] The relationship between the static stability $N^{2}$ and the mixing in the tropopause inversion layer (TIL) is investigated using in situ aircraft observations during SPURT (trace gas transport in the tropopause region). With a new simple measure of mixing degree based on $\mathrm{O}_{3}-\mathrm{CO}$ tracer correlations, high $\mathrm{N}^{2}$ related to an enhanced mixing in the extratropical mixing layer is found. This relation becomes even more pronounced if fresh mixing events are excluded, indicating that mixing within the TIL occurs on a larger than synoptic timescale. A temporal variance analysis of $N^{2}$ suggests that processes responsible for the composition of the TIL take place on seasonal timescales. Using radiative transfer calculations, we simulate the influence of a change in $\mathrm{O}_{3}$ and $\mathrm{H}_{2} \mathrm{O}$ vertical gradients on the temperature gradient and thus on the static stability above the tropopause, which are contrasted in an idealized nonmixed atmosphere and in a reference mixed atmosphere. The results show that $N^{2}$ increases with enhanced mixing degree near the tropopause. At the same time, the temperature above the tropopause decreases together with the development of an inversion and the TIL. In the idealized case of nonmixed profiles the TIL vanishes. Furthermore, the results suggest that $\mathrm{H}_{2} \mathrm{O}$ plays a major role in maintaining the temperature inversion and the TIL structure compared to $\mathrm{O}_{3}$. The results substantiate the link between the extratropical mixing layer and the TIL.

Citation: Kunz, A., P. Konopka, R. Müller, L. L. Pan, C. Schiller, and F. Rohrer (2009), High static stability in the mixing layer above the extratropical tropopause, J. Geophys. Res., 114, D16305, doi:10.1029/2009JD011840.

\section{Introduction}

[2] The tropopause region is of major interest because of its role in the radiative forcing of surface temperatures and the relevance of coupling between climate, chemistry and dynamics in the upper troposphere and lower stratosphere (UT/LS).

[3] The highest static stability (buoyancy frequency squared, $N^{2}$ ) in the atmosphere is located above the tropical and above the extratropical tropopause within the so-called tropopause inversion layer (TIL) [Birner et al., 2006]. The vertical temperature gradient exhibits a strong inversion within this layer with the temperature strongly increasing above a sharp thermal tropopause [Birner et al., 2002]. $N^{2}$ is maximized within the TIL, i.e., at enhanced values compared to values of $N^{2}$ in the entire stratosphere. There is a more intensive TIL during summer than in winter.

[4] The extratropical tropopause region is further characterized as a mixing layer [Fischer et al., 2000; Hoor et al., 2002]. Correlations between a stratospheric $\left(\mathrm{O}_{3}\right)$ and a

\footnotetext{
${ }^{1}$ Institut für Chemie und Dynamik der Geosphäre: Stratosphäre (ICG-1), Forschungszentrum Jülich, Jülich, Germany.

${ }^{2}$ Institut für Chemie und Dynamik der Geosphäre: Troposphäre (ICG-2), Forschungszentrum Jülich, Jülich, Germany.

${ }^{3}$ Atmospheric Chemistry Division, National Center for Atmospheric Research, Boulder, Colorado, USA.
}

Copyright 2009 by the American Geophysical Union. 0148-0227/09/2009JD011840 tropospheric tracer $(\mathrm{CO})$ indicate a large seasonal variability of exchange across the tropopause with the strongest exchange between the troposphere and the stratosphere in summer [Hoor et al., 2002].

[5] The tropopause region is, moreover, a region where the atmospheric radiative balance is very sensitive to changes in trace gases. Mixing processes in this region are responsible for a change in the vertical gradients of $\mathrm{H}_{2} \mathrm{O}$ and $\mathrm{O}_{3}$, which play a key role in radiative balance. An enhancement of $\mathrm{H}_{2} \mathrm{O}$ near the tropopause contributes to a cooling and an enhancement of $\mathrm{O}_{3}$ to a warming of the UT/ LS region [Forster, 1999; Forster and Shine, 2002]. Therefore changes in trace gases in the LS influence the temperature gradient and thus the static stability $N^{2}$ in the TIL. Randel et al. [2007] suggested that the radiative effects of both $\mathrm{O}_{3}$ and $\mathrm{H}_{2} \mathrm{O}$ near the tropopause may be a substantial contribution to the formation and the maintenance of the TIL. They further postulate that the vertical scale of TIL is partly linked to the thickness of the mixing layer.

[6] Other mechanisms have also been suggested to contribute to the maintenance of the TIL. Birner [2006] argued that the TIL could be the result of poleward heat fluxes together with extratropical baroclinic eddies. These eddies act on the background temperature gradient in the tropopause region. Balanced dynamics studies by Wirth [2003] revealed enhanced $N^{2}$ in the LS as a feature of anticyclonic upper tropospheric flow. Thus the TIL could also be the result of anticyclonic influence. Recently Hegglin et al. [2009] delivered further observational support for the 
mechanism proposed by Randel et al. [2007] and emphasized the relevance of $\mathrm{H}_{2} \mathrm{O}$ for maintaining the TIL. The seasonal changes of $\mathrm{H}_{2} \mathrm{O}$ satellite data and their relative vertical gradient are similar to the $N^{2}$ structure within the TIL.

[7] Based on in situ observations and radiative calculations, the present study further investigates the extent to which the TIL is linked to the extratropical mixing layer. To quantify the relationship between the static stability $N^{2}$ and the mixing degree near the extratropical tropopause we introduce a measure to determine the mixing degree using the observations obtained during the SPURT (trace gas transport in the tropopause region) aircraft campaigns. In addition, we performed radiative calculations similar to Randel et al. [2007]. The results further quantify the radiative contribution of $\mathrm{O}_{3}$ and $\mathrm{H}_{2} \mathrm{O}$ to the temperature inversion above the extratropical tropopause in a transition from the special case of nonmixed (L-shaped) to the mixed ECMWF reference mean vertical trace gas profiles.

\section{Data and Methods}

[8] The $\mathrm{CO}$ and $\mathrm{O}_{3}$ measurements from the eight SPURT aircraft campaigns over Europe between 2001 and 2003 [Engel et al., 2006] are analyzed to deduce the mixing degree in the tropopause region and the link to the TIL. One of the aims of these campaigns was to improve the theoretical understanding of the governing processes in the extratropical tropopause region. Thus the obtained data sets represent the UT/LS up to $3.5 \mathrm{~km}$. Each season is captured by eight flights. Our analysis comprises 34 SPURT flights with sufficient data in the vicinity of the tropopause.

[9] The static stability $N^{2}$ is calculated from ECWMF data and is interpolated on the SPURT flight paths. The T511L61 operational ECMWF data [Simmons et al., 2005] are used. The data are interpolated to a $1^{\circ} \times 1^{\circ}$ horizontal grid and to 35 vertical pressure levels (19 equidistant levels between $1000 \mathrm{hPa}$ and $100 \mathrm{hPa}$ ). The interpolation on the flight path is done both spatially, i.e., in the horizontal and vertical space, and temporally. First the respective positions of the SPURT flight paths at noon time (12 UTC) are determined by trajectory calculations with CLaMS (Chemical Lagrangian Model of the Stratosphere [McKenna et al., 2002]). Then the spatial interpolation is done. The vertical resolution of $\Delta \mathrm{z} \sim 0.8-1.4 \mathrm{~km}$ around the extratropical tropopause and the horizontal resolution of $1^{\circ} \times 1^{\circ}$ are sufficient to resolve a well-pronounced TIL in the time and zonal mean. To preserve the features of the tropopause variable in space and time, the relevant variables are first interpolated on equidistant vertical levels relative to the thermal tropopause before calculating $N^{2}$ using a tropopause-based coordinate system following Birner [2006].

\section{Results}

\subsection{SPURT Case Study: Static Stability Within the Mixing Layer}

[10] Figure 1a shows the tracer correlation of $\mathrm{O}_{3}$ and $\mathrm{CO}$ observed during the SPURT flight on 27 April 2003. We define the air with $\mathrm{CO}<34$ ppbv as stratospheric (pink) and the air with $\mathrm{O}_{3}<75$ ppbv as tropospheric (yellow). All other air masses are considered to be mixed (cyan). The highest values of static stability $\left(N^{2} \approx 7 \cdot 10^{-4} \mathrm{~s}^{-2}\right)$ can be found in the middle and upper part of the mixed branch (box 1, Figure $1 \mathrm{~b})$. The lowest values $\left(N^{2} \approx 1 \cdot 10^{-4} \mathrm{~s}^{-2}\right)$ are found in the troposphere and intermediate values $\left(N^{2} \approx 4 \cdot 10^{-4}\right.$ $\mathrm{s}^{-2}$ ) in the stratosphere. Thus the mixing layer contains a significant amount of high stability air.

[11] The vertical cross section of $N^{2}$ along the flight path (bottom) shows that these mixed air masses (cyan flight segment) with high $N^{2}$ (deep red filled contours) were detected immediately after entering the stratosphere at the beginning of the flight. During this flight segment the TIL was sampled (denoted (1), see also Figure 1b). Thereafter, stratospheric air masses with lower $N^{2}$ were observed (pink flight segment) before again entering into a mixed air mass in the vicinity of the jet stream (red contours) with a higher $N^{2}$ than in the entire stratosphere and a lower $N^{2}$ than in the TIL. Box 2 shows the corresponding part in Figure $1 \mathrm{~b}$.

[12] The mixed branch in the vicinity of the jet is likely the result of recent quasi-isentropic mixing of trace gases from the troposphere to the stratosphere. Mean age of air calculations with CLaMS reveal that these mixed air masses close to the jet stream are younger than the mixed air masses in the TIL (not shown). The younger air masses are partly below the thermal tropopause (dark gray circles, Figure 1b). The older air masses within the TIL are above the tropopause (light gray squares, Figure 1b) and far away from the jet.

\subsection{A New Measure of Mixing Degree in the Extratropical UT/LS}

[13] To investigate the relationship between static stability $N^{2}$ and mixing in the UT/LS during all SPURT flights, a measure for quantifying the mixing degree deduced from tracer correlations is proposed. This parameter $f_{\text {mix }}$ depends on the location of the mixing points in a tracer correlation plot and is shown for all SPURT flights in Figure 2 (left). $f_{\text {mix }}$ is designed to measure both the distance to the undisturbed stratospheric $(\mathrm{CO}<34 \mathrm{ppbv})$ and tropospheric $\left(\mathrm{O}_{3}<75 \mathrm{ppbv}\right)$ reservoirs (gray) and the distance to the intersection point (red point) of the mixing-limit lines in the tracer space. This point is identical to the so-called "chemopause" in the work of Pan et al. [2004] and defines here the idealized "L-shaped" tracer correlation. Thus the functional relationship $f_{\text {mix }}$ depends on two different terms according to

$$
f_{\text {mix }}(x, y)=f_{W H}(x, y) \cdot f_{0}(x, y),
$$

with dimensionless variables $x$ for $\mathrm{CO}$ and $y$ for $\mathrm{O}_{3}$. The trace gases are normalized by their respective maxima $\left(\mathrm{O}_{3}=\right.$ 1000 ppbv, $\mathrm{CO}=192 \mathrm{ppbv}$ ) as observed during SPURT and by the limits of the mixing layer according to $\mathrm{x}=(\mathrm{CO}-$ $34 \mathrm{ppbv}) / 192 \mathrm{ppbv}$ and $\mathrm{y}=\left(\mathrm{O}_{3}-75 \mathrm{ppbv}\right) / 1000 \mathrm{ppbv}$. $f_{\text {mix }}(x, y)$ is valid within the mixing area in the correlation plot (color coded in Figure 2, left), i.e., the original reservoirs (gray) are considered to be unmixed with $f_{\text {mix }}(x, y)=0$. The two terms $f_{W H}(x, y)$ and $f_{0}(x, y)$ are described in detail in the following.

[14] In a correlation plot, the mixing degree depends on the distance to the original undisturbed reservoirs of the troposphere and stratosphere. Thus the distance to the bisecting line (gray dashed line) between the two original 

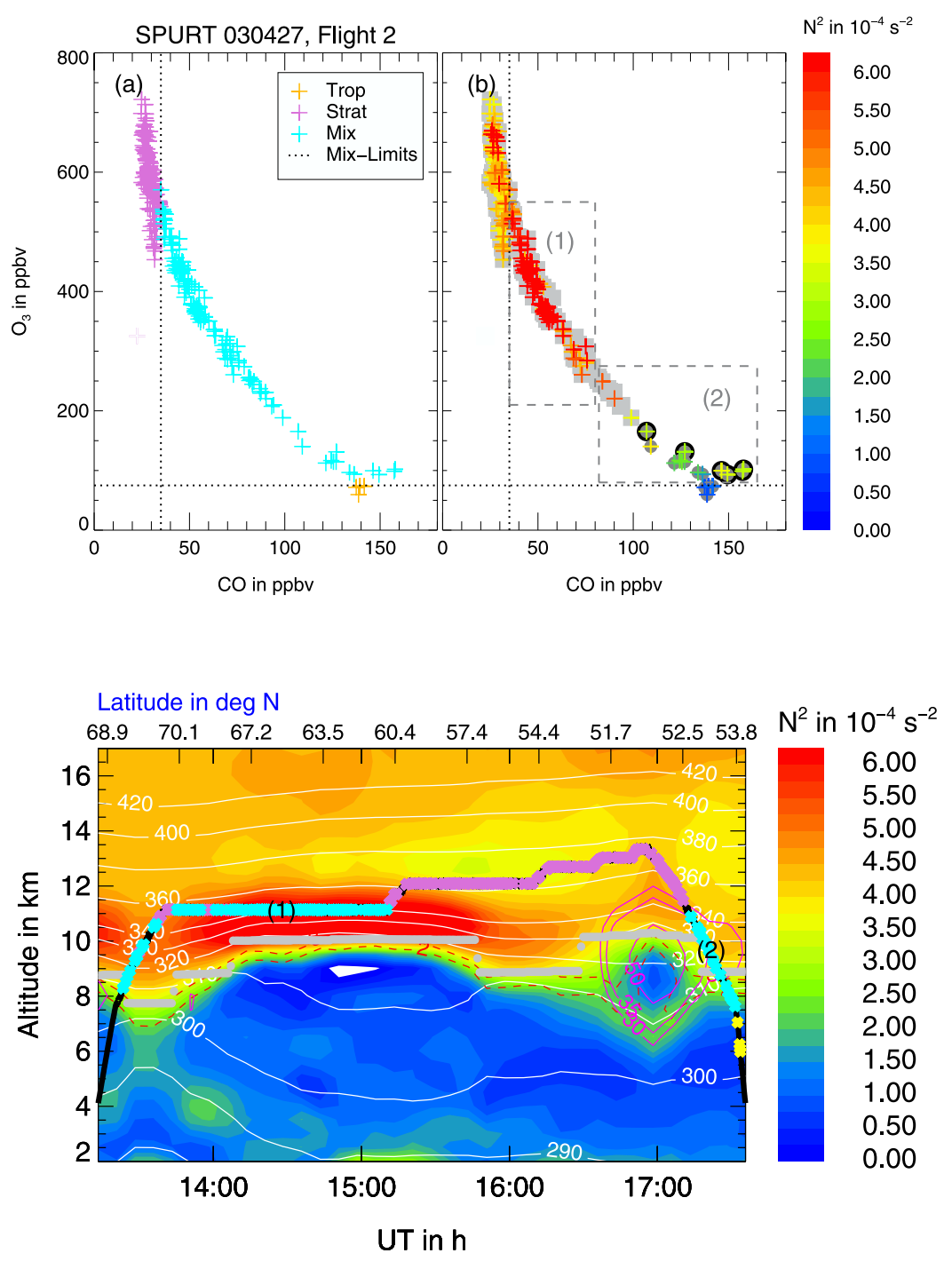

Figure 1. SPURT flight on 27 April 2003 from Kiruna $\left(68^{\circ} \mathrm{N}, 21^{\circ} \mathrm{E}\right)$ toward Hohn $\left(54^{\circ} \mathrm{N}, 9^{\circ} \mathrm{E}\right)$. (top) $\mathrm{O}_{3}$ and $\mathrm{CO}$ correlation colored according to the stratosphere (pink), troposphere (yellow), and mixed branch (cyan) in Figure 1a and according to $N^{2}$ in Figure 1b. Measurements above the thermal tropopause are marked by light gray squares and those below by dark gray circles, which are additionally bordered in black if they are above the dynamical tropopause (2 PVU). Vertical cross section of $N^{2}$ along the flight path (black), colored according to the three branches in Figure 1a (bottom). The mixed parts (cyan) at the beginning and end of the flight path are numbered and marked in Figure $1 \mathrm{~b}$ as gray dashed boxes. Isotaches in $\mathrm{m} \mathrm{s}^{-1}$ (red), 2 and 3 PVU isolines (red dashed), isentropes in $\mathrm{K}$ (white), and the thermal tropopause (gray) are shown.

reservoirs must be accounted for to find the strongest mixing degree in the vicinity of this line and the lowest one close to the original reservoirs. This can be described by the function

$$
f_{W H}(x, y)=\left\{\begin{array}{lll}
\frac{y}{x} & \text { if } & y<x \\
\frac{x}{y} & \text { if } & x<y .
\end{array}\right.
$$

The function $f_{W H}(x, y)$ is also motivated by the entropybased measure of mixing at the tropopause introduced by Patmore and Toumi [2006], who divided the tracer space into five mixing states to quantify the mixing degree. These divisions are similar to the function $f_{W H}(x, y)$ with the most mixed air mass furthest away from the original reservoirs. Using $\mathrm{O}_{3}-\mathrm{CO}$ correlations mixing can be represented by straight lines between the two nonmixed reservoirs of the stratosphere and troposphere in an idealized manner [Hoor et al., 2002; Pan et al., 2007]. The mixing degree further depends on the distance of these mixing lines to the intersection point of both mixing-limit lines (red point in Figure 2), i.e., the greater the distance of a particular mixing line from this point the more strongly the corresponding stratosphere-troposphere exchange event is dominated by mixing. This mixing feature is described by the second functional relationship

$$
f_{0}(x, y)=x+y,
$$



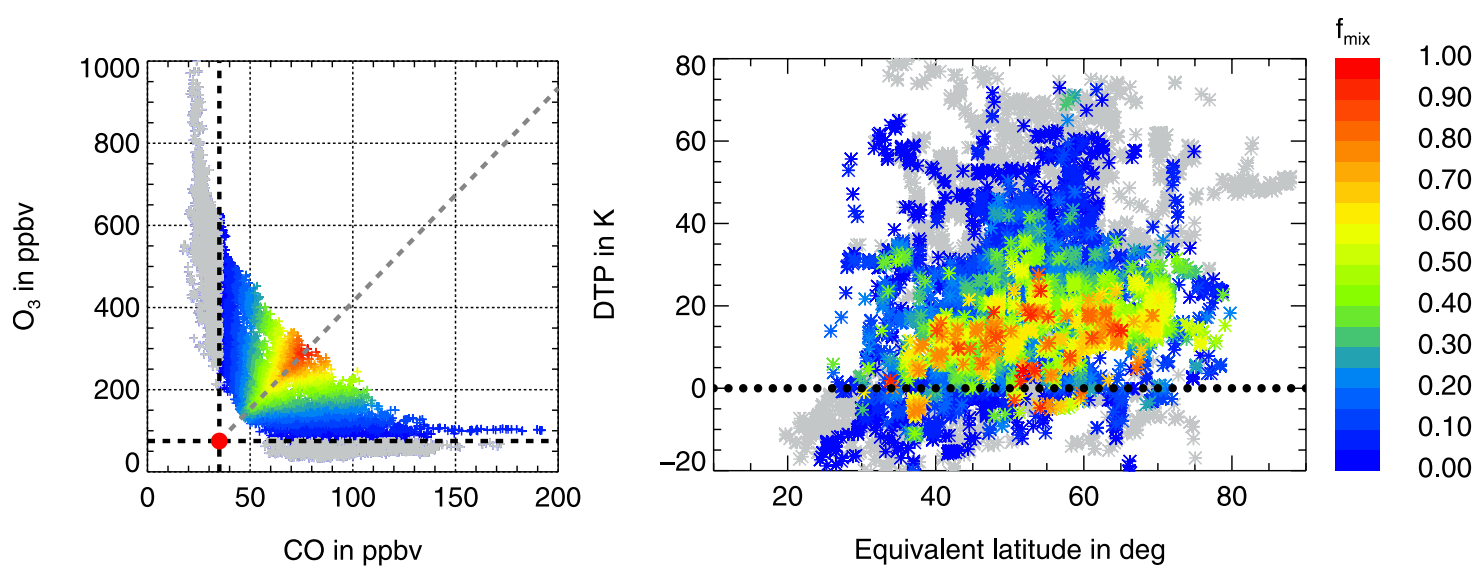

Figure 2. $\mathrm{O}_{3}$ and $\mathrm{CO}$ correlation of all SPURT measurements highlighted with the developed dimensionless measure $f_{\text {mix }}$ to quantify mixing (left). Intersection point of mixing-limit lines as red point and the bisecting line as gray dashed. Mixed region (color coded with $f_{\text {mix }}$ ) depending on the distance to tropopause (DTP), defined as PV $=2$ PVU surface, and the equivalent latitude (right). Stratospheric and tropospheric reservoirs in gray for both panels.

which assigns a mixing degree relative to the intersection point of mixing-limit lines. The resulting dimensionless measure of the mixing degree $f_{\text {mix }}(x, y)$ according to equation (1) is largest in the vicinity of the bisecting line between the two reservoirs (gray dashed) and decreases both toward the unmixed reservoirs (gray) and toward the intersection point (Figure 2 , left). $f_{\text {mix }}(x, y)$ is scaled by its local maximum value $f_{\text {mix }}^{\max } \approx 0.45$ at the bisecting line for SPURT measurements to receive values of $f_{\text {mix }}(x, y)$ between 0 and 1 . Thus the mixing degree $f_{\text {mix }}(x, y)$ is designed as a measure of how much the air mass deviates from the background stratosphere and troposphere due to the mixing in its history. Mixing, as it is diagnosed in the $\mathrm{CO}-\mathrm{O}_{3}$ tracer space by $f_{\text {mix }}(x, y)$, is a very simple representation of a full threedimensional process. Different mixing scenarios can leave the same signature in the $\mathrm{CO}-\mathrm{O}_{3}$ tracer space, i.e., for a given point in the $\mathrm{CO}-\mathrm{O}_{3}$ tracer space, it is not possible to reconstruct the mixing line along which mixing of air masses has occurred. Thus $f_{\text {mix }}(x, y)$ as proposed here is an empirical attempt to quantify the mixing degree by using only the measurable quantities $\left(\mathrm{CO}\right.$ and $\left.\mathrm{O}_{3}\right)$. In particular, the highest function scores for $\mathrm{CO}-\mathrm{O}_{3}$ tracer values far away from the undisturbed reservoirs and far away from the intersection point of mixing-limit lines represent mixing lines which connect those parts of the troposphere and stratosphere which in an undisturbed atmosphere are also geometrically far away from each other. Thus a high mixing degree expected in such "strong mixing events" is measured by high values of $f_{\text {mix }}$.

[15] Figure 2 (right) shows the meridional distribution of $f_{\text {mix }}(x, y)$. The equivalent latitude is used as meridional coordinate, which is inferred from the PV distribution on isentropes according to Nash et al. [1996]. The vertical coordinate DTP is the distance to the dynamical tropopause $\mathrm{TP}_{\mathrm{dyn}}=2 \mathrm{PVU}$ in potential temperature space. The meridional distribution of $f_{\text {mix }}(x, y)$ peaks for strongly mixed air masses just above the dynamical tropopause. When the distribution is calculated relative to the thermal tropopause, the largest $f_{\text {mix }}(x, y)$ is found around the thermal tropopause (not shown). An advantage of this simple function $f_{\text {mix }}(x, y)$ compared with the approach of Patmore and Toumi [2006] is the fact that no further physical parameters have to be introduced and the mixing degree is characterized by a continuous variable.

\subsection{Static Stability and Mixing Degree in the TIL}

[16] The case study in Figure 1 reveals that the mixing layer contains air masses within the TIL above the thermal tropopause $\mathrm{TP}_{\text {th }}$ (box 1) and air masses freshly mixed from the troposphere with a lower $N^{2}$ (box 2).

[17] Figure 3a shows the corresponding correlation of all SPURT $\mathrm{O}_{3}$ and $\mathrm{CO}$ measurements colored according to the static stability $N^{2}$. To identify air masses within the TIL we select all the data above the thermal tropopause $\mathrm{TP}_{\text {th }}$ with a high static stability $\left(\mathrm{N}^{2}>5 \cdot 10^{-4} \mathrm{~s}^{-2}\right)$ and at a close distance to the dynamical tropopause (DTP $<30 \mathrm{~K}$ ). In the following we denote these observations as "TIL branch". The second selection criterion is motivated by the definition of the TIL by Bian and Chen [2008] and the value of $30 \mathrm{~K}$ seems appropriate considering the thickness of the layer above the tropopause with enhanced mixing degree $f_{\text {mix }}$ (Figure 2, right). On the other hand, the mixing layer also consists of freshly mixed air masses from the troposphere that can be identified as those data points between the dynamical tropopause $\mathrm{TP}_{\mathrm{dyn}}$ and the thermal tropopause $\mathrm{TP}_{\text {th }}$, hereafter denoted as "Tropospheric Freshly Mixed (TFM) branch".

[18] The corresponding plots in Figures $3 b$ and $3 c$ show a mean static stability of $N_{\text {mean }}^{2}=6.21 \cdot 10^{-4} \mathrm{~s}^{-2}$ within the TIL branch and a lower mean static stability of $N_{\text {mean }}^{2}=3.78$. $10^{-4} \mathrm{~s}^{-2}$ in the TFM branch of the mixing layer. There is a clear difference in mean static stability for these two branches as expected due to the selection of data above and below the thermal tropopause. Furthermore, the lower boundary of the TFM branch is defined by the dynamical tropopause $\mathrm{TP}_{\mathrm{dyn}}=2 \mathrm{PVU}$ (colored in Figure 3c). The mean potential vorticity value at the thermal tropopause locations during all SPURT flights is calculated to $\mathrm{TP}_{\mathrm{dyn}} \approx 4 \mathrm{PVU}$ and a selection of the TFM branch according to this value is additionally shown as gray bordered dots (Figure 3c). Air 


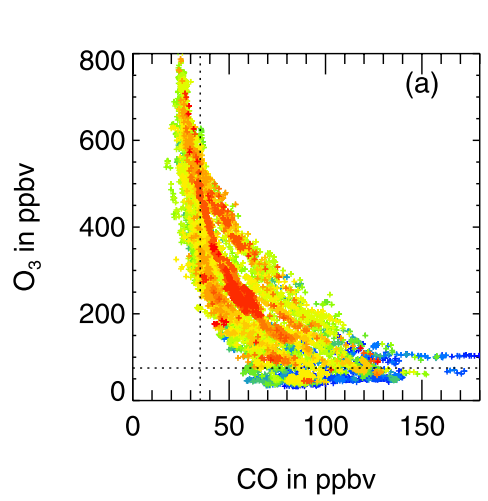

TIL branch

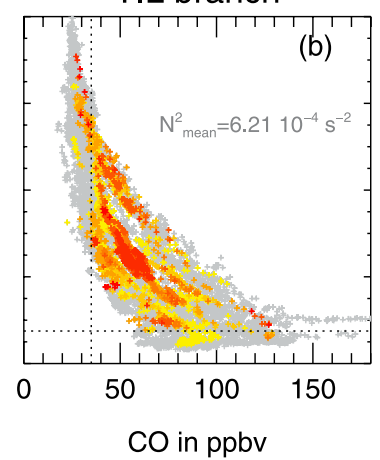

TIL branch
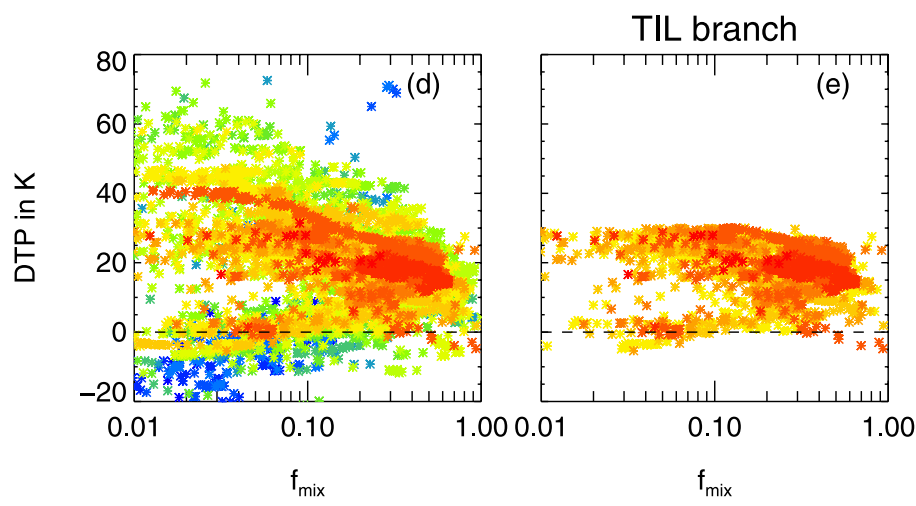

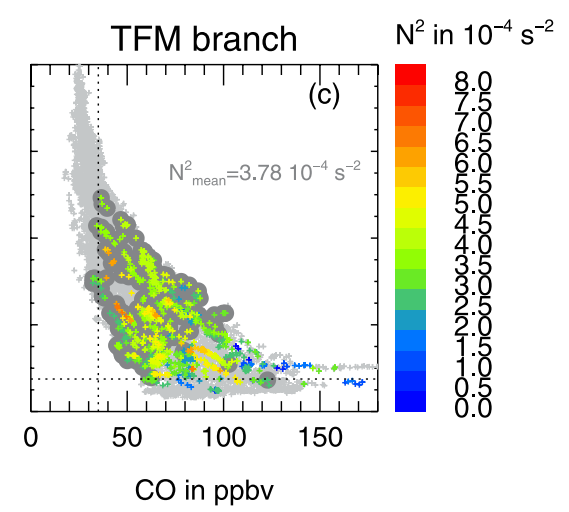

Figure 3. $\mathrm{O}_{3}$ and $\mathrm{CO}$ tracer correlation colored according to the static stability $N^{2}$ in $10^{-4} \mathrm{~s}^{-2}$ for (a) all SPURT measurements, (b) those within the TIL, and (c) the tropospheric freshly mixed (TFM) branch. Dependence of $N^{2}$ on the distance to the dynamic tropopause $\mathrm{TP}_{\mathrm{dyn}}=2 \mathrm{PVU}$ and $f_{\text {mix }}$ for (d) the entire mixing layer, (e) the TIL, and (f) TFM branch between $\mathrm{TP}_{\mathrm{dyn}}(2 \mathrm{PVU})$ and $\mathrm{TP}_{\text {th. }}$. Data between $\mathrm{TP}_{\mathrm{dyn}}(4 \mathrm{PVU})$ and $\mathrm{TP}_{\mathrm{th}}$ are bordered in dark gray (Figures $3 \mathrm{c}$ and $\left.3 \mathrm{f}\right)$.

masses between the dynamical and thermal tropopause on average have PV values roughly between 2 PVU to 4 PVU, which from a PV dynamics point of view supports our notation of "freshly mixed". Both the TFM and the TIL branch lie well within the mixing layer, with the TIL branch partly penetrating the stratospheric reservoir. There are only a few values of the TIL within the troposphere because of the lower boundary $\mathrm{TP}_{\mathrm{dyn}}$.

[19] Figure 3d shows the relation between $N^{2}$ and $f_{\text {mix }}$ within the entire mixing layer dependent on the distance to the dynamical tropopause $\mathrm{TP}_{\text {dyn }}=2 \mathrm{PVU}$. At a mixing degree of $f_{\text {mix }}>0.2$, a high $N^{2}$ is observed and the vertical extension of the mixing layer is close to the tropopause. At a very low mixing degree of $f_{\text {mix }}=0.05$, the mixing layer extends between $-20 \mathrm{~K}$ to $60 \mathrm{~K}$ around the dynamical tropopause, at a high mixing degree of $f_{\text {mix }}=0.6$ mainly up to $30 \mathrm{~K}$ above the tropopause. A figure using the distance to the thermal tropopause in $\mathrm{km}$ as vertical coordinate shows that the high $N^{2}$ values at low mixing degree $f_{\text {mix }}<0.1$ more than $30 \mathrm{~K}$ above the dynamical tropopause are within $2 \mathrm{~km}$ above the thermal tropopause (not shown). These values are i.a. observed in the vicinity of secondary tropopauses connected to a jet stream, when the distance relative to $\mathrm{TP}_{\mathrm{dyn}}$ may be larger than relative to $\mathrm{TP}_{\text {th }}$. The region of high $N^{2}$ identified by high $f_{\text {mix }}$ lies within the TIL (Figure 3e). The TFM branch with a lower $N^{2}$ extends up to DTP $=40 \mathrm{~K}$ (Figure $3 \mathrm{f}$ ). Values above DTP $=20 \mathrm{~K}$ are associated with mixing events in the vicinity of secondary tropopauses, when the distance between $\mathrm{TP}_{\mathrm{dyn}}$ and $\mathrm{TP}_{\text {th }}$ becomes very large. Due to the prevailing dynamical situation, the PV isolines are deformed and thus $\mathrm{TP}_{\mathrm{dyn}}$ and $\mathrm{TP}_{\text {th }}$ diverge.

[20] The relation between $N^{2}$ and the mixing degree described by $f_{\text {mix }}$ is also shown as a probability distribution function (Figure 4). For this purpose $0.5 \cdot 10^{-4} \mathrm{~s}^{-2}$ bins for $N^{2}$ and 0.1 bins for $f_{\text {mix }}$ are calculated. Each $N^{2}$ bin is normalized, i.e., the probability (color coding) reflects the percentage of the mixing degree $f_{\text {mix }}$ in a single $N^{2}$ interval. There is a positive correlation between the two quantities in the entire mixing layer (Figure 4a). The Spearman's rank correlation is around $\mathrm{k}=0.25$. When the mixing layer is split into the TIL branch (Figure 4b) and TFM branch (Figure 4c) again, we find a lower correlation coefficient of $\mathrm{k}=0.11$ for the relation within the TFM branch and a higher one of $k=0.43$ in the TIL branch. Especially in the TIL branch, the mean $f_{\text {mix }}$ (gray lines) per $N^{2}$ bin increases with $N^{2}$ and most data points are located around this mean $f_{\text {mix }}$. This is demonstrated by the bordered bins with more than 30 data points (orange line). There is no clear relationship between $f_{\text {mix }}$ and $N^{2}$ in the TFM branch and there is a negative correlation for $N^{2}>4 \cdot 10^{-4} \mathrm{~s}^{-2}$. The higher correlation $\mathrm{k}=0.43$ within the TIL branch suggests a connection between the TIL with enhanced $N^{2}$ and the mixing layer above the tropopause. This correlation is tested with the bootstrap method [Press et al., 2002] and with simulated data sets reproducing the observed timescale analysis of $N^{2}$ (shown in Figure 5) and $f_{\text {mix }}$. The level of 

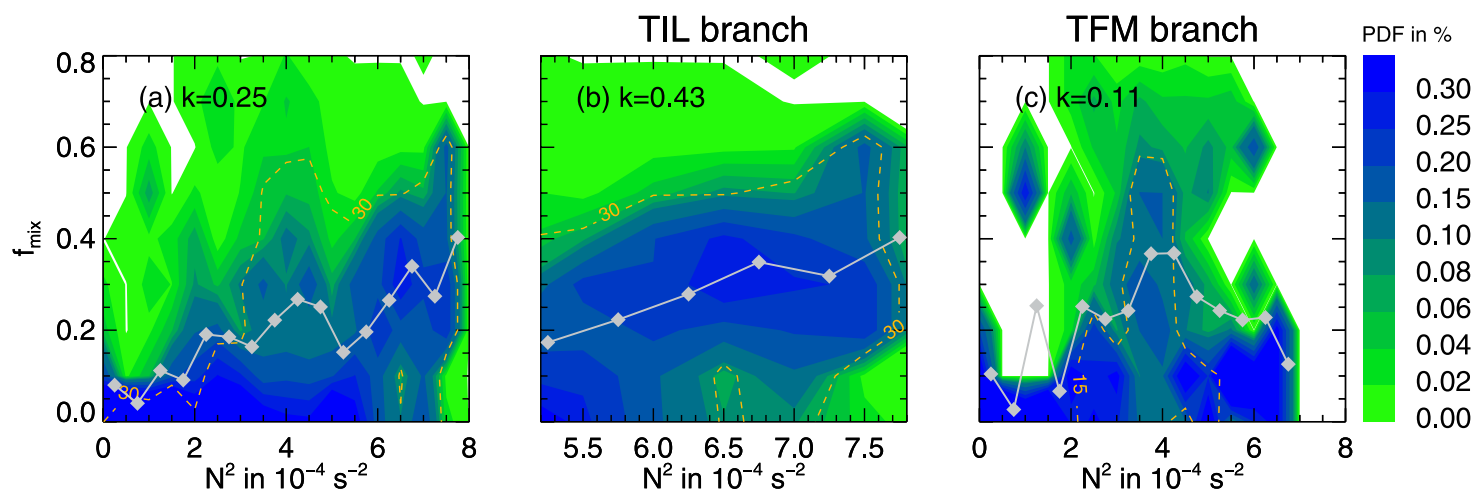

Figure 4. Correlation between the mixing degree $f_{\text {mix }}$ and $N^{2}$ as probability distribution functions for (a) the entire mixing layer, (b) TIL branch, and (c) TFM branch. The bin size is $0.510^{-4} \mathrm{~s}^{-2}$ for $N^{2}$ and 0.1 for $f_{\text {mix }}$. Each $N^{2}$ bin is normalized, i.e., the probability (color coding) reflects the percentage of the mixing degree $f_{\text {mix }}$ in a single $N^{2}$ interval. The gray solid line shows the mean $f_{\text {mix }}$ in each $N^{2}$ interval and the area with a bin size larger than 30 (15 in case of TFM branch) is bordered by the orange line. Spearman's rank correlation coefficients $k$ are additionally shown (top left).

significance for the null hypothesis $\mathrm{k}=0$ is 0.06 at an error probability of 0.01 . Thus the null hypothesis has to be rejected and the correlation $\mathrm{k}=0.43$ in the TIL branch is significant.

[21] Nevertheless, $\mathrm{k}=0.43$ implicates that the dominant amount of $N^{2}$ variance is caused by processes which are uncorrelated to $f_{\mathrm{mix}}$. One cause is the artificial variance in $N^{2}$ because of errors due to the determination of $N^{2}$ from ECMWF fields by trajectory calculations to noon time, which might represent $N^{2}$ on a larger grid than appropriate for the aircraft. With sensitivity studies we estimated the scale of this effect to be one third of the total variance of $N^{2}$. This let us expect an improved correlation if artificial sources of variance would be removed.

[22] In order to investigate the different timescales of atmospheric processes which play a role within the TIL and TFM branch (Figure 3), the temporal $N^{2}$ variances in these branches are shown in Figure 5 (green and orange lines, respectively). A temporal variance analysis [Rohrer and Berresheim, 2006; Kunz et al., 2008] provides information on the atmospheric processes which influence the variability of specific atmospheric parameters such as $N^{2}$. Around $80 \%$ of the total $N^{2}$ variance within the TFM branch is already achieved after 8 days (gray-green dot), the same fraction of total $N^{2}$ variance in the TIL branch is achieved after 360 days (gray-orange dot). The analysis suggests that fresh mixing from the troposphere in the TFM branch plays a role on a synoptic timescale of up to 8 days (green dashed, Figure 5). Processes which contribute to the formation of the TIL may occur rather on a seasonal timescale up to 360 days (orange dashed line, Figure 5). The $N^{2}$ variance increases on the seasonal timescale and there is no enhancement on the synoptic timescale within the TIL branch. The seasonal timescale is required for radiative adjustment in the atmosphere. The $N^{2}$ variance within the TIL branch starts to increase on a timescale of more than 60 days. The problem of under-represented data bins roughly between 10 and 90 days was already discussed by Kunz et al. [2008]. The variance thus remains unchanged on the interseasonal timescales. For smaller timescales, which are represented by sufficient measurement data, the variance changes. Thus the exact seasonal timescale when the variance increases again may be influenced.

\subsection{Radiative Forcing as a Mechanism for Maintaining the TIL}

[23] The change of $N^{2}$ caused by different mixing states and thus different trace gas gradients in the tropopause region is now investigated with radiative transfer calculations similar to those of Randel et al. [2007]. They assumed certain perturbations of the $\mathrm{O}_{3}$ and $\mathrm{H}_{2} \mathrm{O}$ profiles and calculated the impact on the temperature profile with a fixed dynamical heating assumption. Here we extend the work of Randel et al. [2007] by deducing the perturbed $\mathrm{O}_{3}$

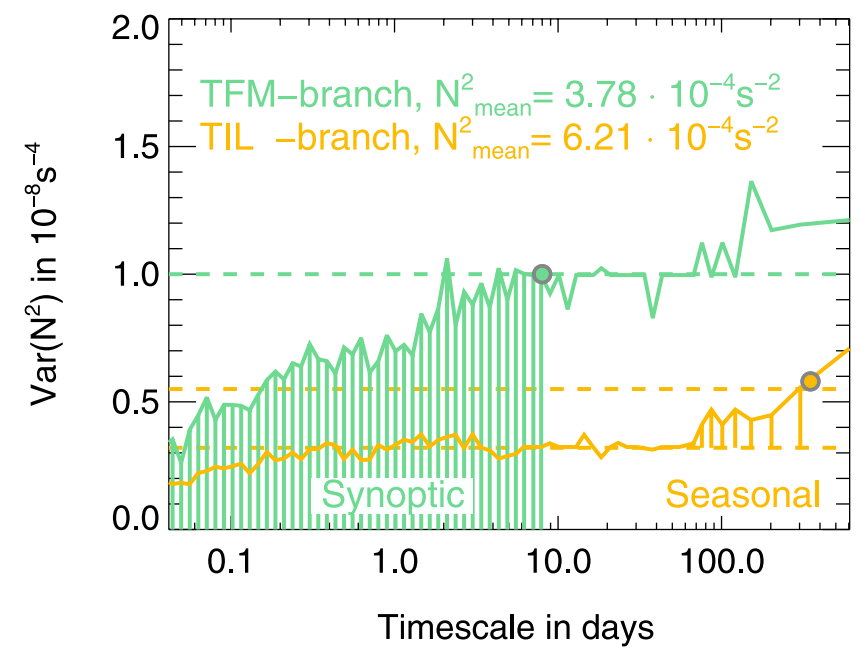

Figure 5. Temporal variance analysis of $N^{2}$ in $10^{-8} \mathrm{~s}^{-4}$ within the TIL (orange line) and TFM branch (green line). The timescale is shown from several minutes to 600 days. $80 \%$ of the total $N^{2}$ variance within the TFM branch and TIL branch is marked by the gray-green or gray-orange dot, respectively. The mean values of $N^{2}$ in $10^{-4} \mathrm{~s}^{-2}$ in both branches are denoted in the legend. The greatest enhancement in variance within the TIL branch is achieved on the seasonal timescale (orange dashed), in contrast to the $N^{2}$ variance in the TFM branch, which is strongest on the synoptic. 

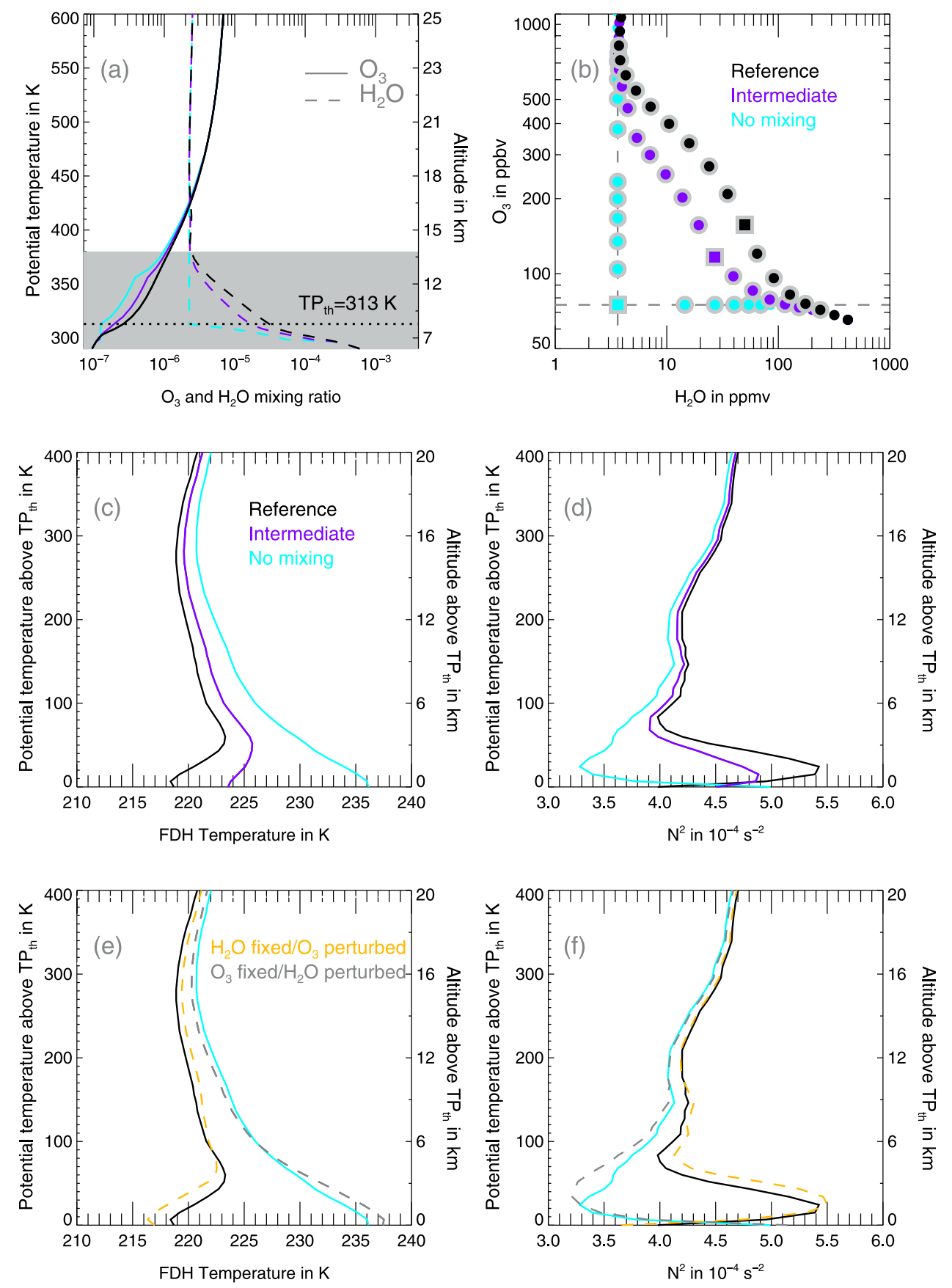

Figure 6. (a) ECMWF mean vertical profiles of $\mathrm{O}_{3}$ (solid lines) and $\mathrm{H}_{2} \mathrm{O}$ (dashed lines) at $60^{\circ} \mathrm{N}$ respective to different states of the atmosphere, i.e., nonmixed (cyan), mixed (black), and intermediate case (purple). Both the potential temperature in $\mathrm{K}$ and the altitude in $\mathrm{km}$ are shown with respect to the thermal tropopause $\left(\mathrm{TP}_{\mathrm{th}}=313 \mathrm{~K}, 9.09 \mathrm{~km}\right)$. (b) Tracer correlations for profiles in different mixing states from Figure 6a. SPURT area is marked by (a) gray shading and (b) dots bordered in gray. (c) Based on fixed dynamical heating $(\mathrm{FDH})$ calculations, resulting temperature profiles for the different mixing states above $\mathrm{TP}_{\text {th. }}$ (d) Static stability $N^{2}$ according to the temperature profiles from Figure $6 \mathrm{c}$. (e, f) The FDH calculations if one of the two trace gases is kept constant: $\mathrm{O}_{3}$ (gray dashed) or $\mathrm{H}_{2} \mathrm{O}$ (yellow dashed).

and $\mathrm{H}_{2} \mathrm{O}$ profiles from differently mixed states determined in $\mathrm{O}_{3}-\mathrm{H}_{2} \mathrm{O}$ tracer correlations and study the impacts on the temperature gradient and the $N^{2}$ structure in the vicinity of the tropopause. In contrast to the work of Randel et al. [2007], here $\mathrm{O}_{3}$ and $\mathrm{H}_{2} \mathrm{O}$ are consistently perturbed in the same altitude region by taking into account their correlation in the UT/LS.
[24] We use tropopause-based zonal and time mean ECMWF vertical profiles of $\mathrm{O}_{3}, \mathrm{H}_{2} \mathrm{O}$ and temperature for all SPURT flight days at $60^{\circ} \mathrm{N}$. This geographical latitude lies well within the TIL and the mixing layer. Figure $6 \mathrm{a}$ shows these mean $\mathrm{O}_{3}$ and $\mathrm{H}_{2} \mathrm{O}$ profiles as black lines both in the potential temperature $[\mathrm{K}]$ and altitude space $[\mathrm{km}]$. The tracer correlation (black dots, Figure $6 \mathrm{~b}$ ) reveals a 
pronounced mixing layer for these ECMWF trace gas profiles. A temperature inversion up to $3.5 \mathrm{~km}(60 \mathrm{~K})$ above the thermal tropopause is also evident in the mean ECMWF temperature (black line, Figure 6c) together with a maximum in the static stability of $N^{2}=5.4 \cdot 10^{-4} \mathrm{~s}^{-2}$ around $1.5 \mathrm{~km}(25 \mathrm{~K})$ above the tropopause (black line, Figure 6d). The area with the available SPURT data in the $\mathrm{UT} / \mathrm{LS}$ is bordered in gray in Figures $6 \mathrm{a}$ and $6 \mathrm{~b}$. We construct hypothetical profiles for nonmixed conditions (cyan lines or dots) assuming the so-called "L-shaped" tracer correlation [Pan et al., 2007]. The nonmixed $\mathrm{H}_{2} \mathrm{O}$ profile decreases in the troposphere and is constant in the stratosphere $(\approx 4$ ppmv in our construction, consistent with the minimum of the mean $\mathrm{H}_{2} \mathrm{O}$ vertical profile at $18 \mathrm{~km}$ ). The nonmixed $\mathrm{O}_{3}$ profile is constant in the troposphere $(\approx 75 \mathrm{ppbv})$ and increases in the stratosphere. The corresponding tracer correlation forms an "L-shape" (cyan dots, Figure 6b). Intermediate $\mathrm{H}_{2} \mathrm{O}$ and $\mathrm{O}_{3}$ profiles (purple lines, Figure 6a) exhibit a mixing line in the area between the nonmixed and mixed reference profiles (purple dots, Figure $6 \mathrm{~b}$ ). The intermediate and nonmixed profiles (purple and cyan) agree with the reference profiles (black) in the stratosphere above $18 \mathrm{~km}$ and in the troposphere below $6 \mathrm{~km}$.

[25] The radiative effects due to the change of $\mathrm{O}_{3}$ and $\mathrm{H}_{2} \mathrm{O}$ from nonmixed (cyan) to mixed reference concentrations (black) are investigated. Sensitivity tests with the perturbed profiles of Figure 6a are performed with the Reading narrowband radiative transfer model [Forster, 1999; Forster and Shine, 2002]. Calculations are performed using the assumption of fixed dynamical heating, i.e., the dynamical contribution to heating is assumed to be the same for the background and perturbation calculations. The related temperature profiles above the thermal tropopause $\mathrm{TP}_{\text {th }}$ are shown in Figure 6c. Above the tropopause the temperature increases throughout the column when the mixing degree is reduced. At the same time, the temperature inversion decreases. An enhanced temperature above the tropopause remains as a net effect of the simultaneous perturbation of $\mathrm{H}_{2} \mathrm{O}$ and $\mathrm{O}_{3}$ according to a transition from a mixed to a nonmixed state. Figure $6 \mathrm{~d}$ shows $N^{2}$ for the newly adjusted temperature profiles corresponding to nonmixed (cyan line) and intermediate mixed (purple) $\mathrm{H}_{2} \mathrm{O}$ and $\mathrm{O}_{3}$ profiles. The perturbation of trace gas profiles in the tropopause region according to a transition from a mixed (black) to a nonmixed (cyan) state reveals a successive decrease of $N^{2}$ the more strongly mixing is reduced. The TIL just above the tropopause vanishes in the case of nonmixed profiles. Above the tropopause where SPURT flights were performed the nonmixed profiles show a temperature increase of $18 \mathrm{~K}$ and an $N^{2}$ reduction of 2.1 . $10^{-4} \mathrm{~s}^{-2}$ compared to realistic mixed profiles. A sole reduction of $\mathrm{O}_{3}\left(\mathrm{H}_{2} \mathrm{O}\right)$ from the mixed to the nonmixed "L-shaped" profile above the tropopause leads to a cooling (warming) in this region (Figure 6e). The contribution of $\mathrm{H}_{2} \mathrm{O}$ to the temperature change $(\approx 5-15 \mathrm{~K}$ up to $4-5 \mathrm{~km}$ above the tropopause) is larger than that of $\mathrm{O}_{3}(\approx 1-2 \mathrm{~K})$. The temperature decrease due to the $\mathrm{O}_{3}$ perturbation is nearly the same up to $4-5 \mathrm{~km}$. The temperature lapse rate remains almost unchanged and there is nearly the same $N^{2}$ profile above the tropopause, especially up to $1.5 \mathrm{~km}$. A temperature inversion is also present for nonmixed $\mathrm{O}_{3}$ profiles (yellow dashed). In the case of nonmixed $\mathrm{H}_{2} \mathrm{O}$ profiles (gray dashed) there is no inversion at all. The temperature inversion becomes stronger the more $\mathrm{H}_{2} \mathrm{O}$ is enhanced toward the mixed reference profile. This suggests that $\mathrm{H}_{2} \mathrm{O}$ plays a larger role in establishing the temperature inversion and the TIL structure than $\mathrm{O}_{3}$. Figure $6 \mathrm{f}$ shows that the $N^{2}$ distribution in case of nonmixed profiles (cyan) up to $1.5 \mathrm{~km}$ above $\mathrm{TP}_{\text {th }}$ is mainly created by the change in $\mathrm{H}_{2} \mathrm{O}$ (gray dashed). This result partly contrasts with the conclusion of Randel et al. [2007], who suggested that $\mathrm{O}_{3}$ and $\mathrm{H}_{2} \mathrm{O}$ play comparable roles in creating the inversion with opposing radiative effects in heating and cooling at slightly different altitude levels. The differences between our results and those of Randel et al. [2007] are probably due to the differences in perturbing the trace gas profiles above the tropopause. This result underlines the importance of a consistent perturbation of $\mathrm{O}_{3}$ and $\mathrm{H}_{2} \mathrm{O}$.

\section{Summary and Discussion}

[26] Based on aircraft measurements of $\mathrm{CO}$ and $\mathrm{O}_{3}$ during SPURT we introduced a dimensionless parameter $f_{\text {mix }}$ to quantify the mixing degree in the extratropical tropopause region. Using this parameter, we investigated the relationship between the static stability $N^{2}$ and the mixing degree and found a positive relation between these two above the tropopause, particularly in the TIL. This is consistent with the hypothesis that mixing contributes to the formation of TIL as suggested by Birner [2006] and Randel et al. [2007]. The current study brings the two characteristics of the UT/ LS, mixing and static stability, together for the first time. Our analysis further shows that the TIL is detectable in high resolution ECMWF fields. In contrast, Birner et al. [2006] argued that the TIL is not well represented in ERA-40 reanalysis data. This difference could be a consequence of unequal assimilation procedures used in the operational (4DVAR) and ERA-40 (3DVAR) data or of different horizontal resolutions of both data sets (T511 versus T159 for operational and reanalysis data, respectively).

[27] Sensitivity studies with a radiation transport model confirm the hypothesis of Randel et al. [2007] that radiative effects of $\mathrm{O}_{3}$ and $\mathrm{H}_{2} \mathrm{O}$ may contribute to the formation and maintenance of the mixing layer and the TIL. The new aspect of our analysis is to emphasize the change in FDH temperature and $N^{2}$ for profiles, which are perturbed consistently to represent a vanishing mixing (L-shaped $\mathrm{O}_{3}$ and $\mathrm{H}_{2} \mathrm{O}$ tracer correlation) in the UT/LS. The temperature inversion and the structure of the TIL does not appear for nonmixed mean vertical profiles of $\mathrm{O}_{3}$ and $\mathrm{H}_{2} \mathrm{O}$. The temperature inversion is strengthened if the concentrations of $\mathrm{O}_{3}$ and $\mathrm{H}_{2} \mathrm{O}$ are enhanced above the extratropical tropopause. Here $\mathrm{H}_{2} \mathrm{O}$ is more dominant than $\mathrm{O}_{3}$ for the development of the temperature inversion and the TIL structure. There is only a small shift in temperature profile if $\mathrm{O}_{3}$ is enhanced from a nonmixed to a mixed reference case at the tropopause.

[28] So far, it has not been possible to identify a particular atmospheric process as sole contributor to the TIL. Like Randel et al. [2007], we conclude that radiation may be an important forcing mechanism in maintaining the TIL together with the dynamic mechanisms discussed by Wirth [2003], Birner [2006], or recently by Son and Polvani 
[2007]. With model simulations based on the dry primitive equations without any radiation, Son and Polvani [2007] also obtained a TIL. Their TIL is not as sharp as in observations and this led them to conclude that synopticscale balanced dynamics alone may not be sufficient to explain the quantitative features of the observed TIL. Therefore Son and Polvani [2007] concluded that more likely radiative processes play an additional important role for the TIL. To determine the exact contributions of radiation and dynamics to the TIL, further modeling studies are needed in future, which may consider both the dynamics and the radiation.

[29] In the light of the activity of radiative and baroclinic forcing, we interpret our results regarding the link between the TIL and the mixing layer as follows:

[30] Synoptic-scale baroclinic eddies in the extratropical tropopause region lead to an isentropic transport of low $\mathrm{O}_{3}$ and high $\mathrm{H}_{2} \mathrm{O}$ mixing ratios from lower to higher latitudes and thus to mixing in the midlatitudes (troposphere to stratosphere transport). These freshly mixed air masses, which can be found mainly below but also above the jet streams, are not necessarily related to high $N^{2}$ values, e.g., the mixed part in the vicinity of the jet stream (Figures 1 and $3 c)$. The atmospheric processes relevant for this fresh mixing are synoptic-scale up to 8 days (Figure 5) and are too short to have radiative effects which may lead to an enhanced $N^{2}$. This also may be the reason for the very low correlation between the mixing degree $f_{\text {mix }}$ and a large $N^{2}$ within the TFM branch. The TIL also contains mixed air masses which have been there longer. The temporal variance analysis suggests a rather seasonal timescale (Figure 5). This is a timescale which is necessary for the atmospheric radiative response to the mixing. Due to the radiative balance in the atmosphere the temperature has already adjusted to the new trace gas concentrations near the tropopause and a temperature inversion has developed with time (Figure $6 \mathrm{c}$, black line). This demonstrates the evolution of $N^{2}$ from the nonmixed case to the intermediate case and finally to the mixed reference case (Figure 6d). This hypothesized mechanism also closes the loop to the discussion by Birner [2006] according to which the strong stratification within the TIL and the large-scale horizontal mixing forces the air that has entered the TIL, to stay there and to be mixed isentropically over large distances. This may provide the basis for the mixing layer to become a climatological feature and for the radiatively active tracers to force the TIL.

[31] Our analysis suggests that the mixing layer contains, on the one hand, older air masses (TIL branch, Figure 3), with high values of $N^{2}$ possibly due to radiative adjustment. This part represents the TIL. On the other hand, there are younger air masses with lower $N^{2}$ values within the mixing layer (TFM branch, Figure 3), because of recent intrusion processes due to the permeability or so-called midlatitude breaks associated with the jet.

[32] Acknowledgments. This work is supported by the HGF programme EOS (Earth Observing System). We thank P. Hoor and $\mathrm{H}$. Fischer for providing the SPURT CO data, P. M. Forster for support and permission to use his radiation scheme, and T. Birner for review and useful discussions on the paper. Furthermore, the reviews and comments of two anonymous referees were very helpful.

\section{References}

Bian, J., and H. Chen (2008), Statistics of the tropopause inversion layer over Beijing, 2008, Adv. Atmos. Sci., 25, 381-386.

Birner, T. (2006), Fine-scale structure of the extratropical tropopause region, J. Geophys. Res., 111, D04104, doi:10.1029/2005JD006301.

Birner, T., A. Dörnbrack, and U. Schumann (2002), How sharp is the tropopause at midlatitudes?, Geophys. Res. Lett., 29(14), 1700, doi:10.1029/2002GL015142.

Birner, T., D. Sankey, and T. G. Shepherd (2006), The tropopause inversion layer in models and analyses, Geophys. Res. Lett., 33, L14804, doi:10.1029/2006GL026549.

Engel, A., et al. (2006), Highly resolved observations of trace gases in the lowermost stratosphere and upper troposphere from the SPURT project: An overview, Atmos. Chem. Phys., 6, 283-310.

Fischer, H., F. G. Wienhold, P. Hoor, O. Bujok, C. Schiller, P. Siegmund, M. Ambaum, H. A. Scheeren, and J. Lelieveld (2000), Tracer correlations in the northern high latitude lowermost stratosphere: Influence of crosstropopause mass exchange, Geophys. Res. Lett., 27(1), 97-100.

Forster, P. M. de F. (1999), Radiative forcing due to stratospheric ozone changes 1979-1997, using updated trend estimates, J. Geophys. Res. 104(D20), 24,395-24,399.

Forster, P. M. de F., and K. P. Shine (2002), Assessing the climate impact of trends in stratospheric water vapor, Geophys. Res. Lett., 29(6), 1086, doi:10.1029/2001GL013909.

Hegglin, M. I., C. D. Boone, G. L. Manney, and K. A. Walker (2009), A global view of the extratropical tropopause transition layer from Atmospheric Chemistry Experiment Fourier Transform Spectrometer $\mathrm{O}_{3}, \mathrm{H}_{2} \mathrm{O}$ and CO, J. Geophys. Res., 114, D00B11, doi:10.1029/2008JD009984.

Hoor, P., H. Fischer, L. Lange, J. Lelieveld, and D. Brunner (2002), Seasonal variations of a mixing layer in the lowermost stratosphere as identified by the $\mathrm{CO}-\mathrm{O}_{3}$ correlation from in situ measurements, J. Geophys. Res., 107(D5), 4044, doi:10.1029/2000JD000289.

Kunz, A., C. Schiller, F. Rohrer, H. G. J. Smit, P. Nedelec, and N. Spelten (2008), Statistical analysis of water vapour and ozone in the UT/LS observed during SPURT and MOZAIC, Atmos. Chem. Phys., 8, 66036615.

McKenna, D., S. Konopka, P. Grooß, U. Günther, and G. Müller (2002), A new chemical Lagrangian model of the stratosphere (CLaMS): 1. Formulation of advection and mixing, J. Geophys. Res., 107(D16), 4309, doi:10.1029/2000JD000114.

Nash, E. R., P. A. Newman, J. E. Rosenfield, and M. R. Schoeberl (1996), An objective determination of the polar vortex using Ertel's potential vorticity, J. Geophys. Res., 101(D5), 9471-9478.

Pan, L. L., W. J. Randel, B. L. Gary, M. J. Mahoney, and E. J. Hintsa (2004), Definitions and sharpness of the extratropical tropopause: A trace gas perspective, J. Geophys. Res., 109, D23103, doi:10.1029/ 2004JD004982.

Pan, L. L., J. C. Wei, D. E. Kinnison, R. R. Garcia, D. J. Wuebbles, and G. P. Brasseur (2007), A set of diagnostics for evaluating chemistryclimate models in the extratropical tropopause region, J. Geophys. Res., 112, D09316, doi:10.1029/2006JD007792.

Patmore, N., and R. Toumi (2006), An entropy-based measure of mixing at the tropopause, Q. J. R. Meteorol. Soc., 132, 1949-1967.

Press, W. H., S. A. Teukolsky, W. T. Vetterling, and B. P. Flannery (2002), Numerical Recipes in C: The Art of Scientific Computing, 2nd ed., pp. 691-692, Cambridge Univ. Press, Cambridge.

Randel, W. J., F. Wu, and P. Forster (2007), The extratropical tropopause inversion layer: Global observations with GPS data, and a radiative forcing mechanism, J. Atmos. Sci., 64, 4489-4496, doi:10.1175/2007JAS2412.1.

Rohrer, F., and H. Berresheim (2006), Strong correlation between levels of tropospheric hydroxyl radicals and solar ultraviolet radiation, Nature, 442, $184-187$.

Simmons, A., M. Hortal, G. Kelly, A. McNally, A. Untch, and S. Uppala (2005), ECMWF analyses and forecasts of stratospheric winter polar vortex breakup: September 2002 in the southern hemisphere and related events, J. Atmos. Sci., 62, 668-689.

Son, S. W., and L. M. Polvani (2007), Dynamical formation of an extratropical tropopause inversion layer in a relatively simple general circulation model, Geophys. Res. Lett., 34, L17806, doi:10.1029/2007GL030564. Wirth, V. (2003), Static stability in the extratropical tropopause region, J. Atmos. Sci., 60, 1395-1409.

P. Konopka, A. Kunz, R. Müller, and C. Schiller, Institut für Chemie und Dynamik der Geosphäre: Stratosphäre (ICG-1), Forschungszentrum Jülich, D-52425 Jülich, Germany. (a.kunz@fz-juelich.de)

L. L. Pan, Atmospheric Chemistry Division, National Center for Atmospheric Research, Boulder, CO 80305, USA.

F. Rohrer, Institut für Chemie und Dynamik der Geosphäre: Troposphäre (ICG-2), Forschungszentrum Jülich, D-52425 Jülich, Germany. 